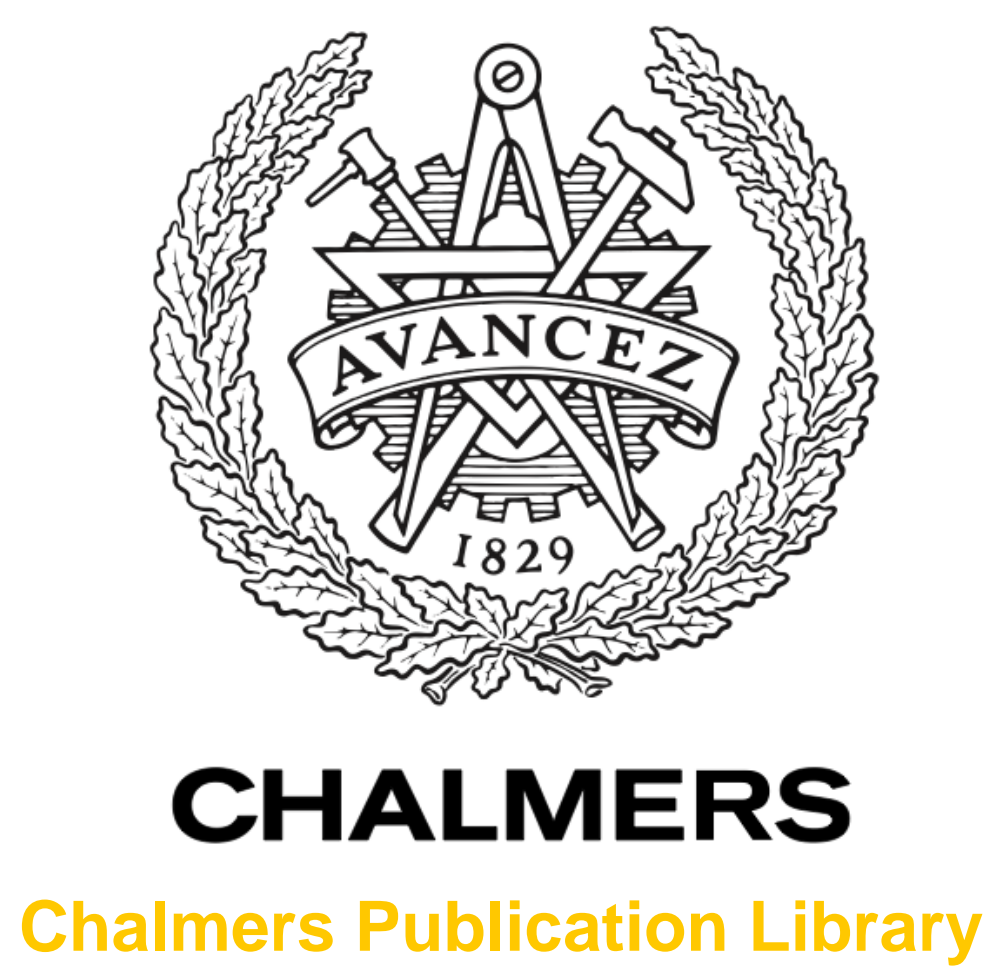

Bridge decks of fibre reinforced polymer (FRP): A sustainable solution

This document has been downloaded from Chalmers Publication Library (CPL). It is the author's version of a work that was accepted for publication in:

Construction and Building Materials (ISSN: 0950-0618)

Citation for the published paper:

Mara, V. ; Haghani, R. ; Harryson, P. (2014) "Bridge decks of fibre reinforced polymer

(FRP): A sustainable solution". Construction and Building Materials, vol. 50 pp. 190-199.

http://dx.doi.org/10.1016/j.conbuildmat.2013.09.03

Down「oaded from: http://publications.lib.chalmers.se/publication/185412

Notice: Changes introduced as a result of publishing processes such as copy-editing and formatting may not be reflected in this document. For a definitive version of this work, please refer to the published source. Please note that access to the published version might require a subscription. 


\title{
BRIDGE DECKS OF FIBRE REINFORCED POLYMER (FRP): A SUSTAINABLE SOLUTION
}

Valbona Mara ${ }^{1}$, Reza Haghani ${ }^{2}$ and Peter Harryson ${ }^{3}$

\begin{abstract}
Fibre reinforced polymer (FRP) bridge decks have become an interesting alternative and they have attracted increasing attention for applications in the refurbishment of existing bridges and the construction of new bridges. The benefits brought by lightweight, high-strength FRP materials to these applications are well recognised. However, the sustainability of bridge concepts incorporating FRP decks still needs to be demonstrated and verified. The aim of this paper is to bridge this knowledge gap by examining the sustainability of these FRP solutions in comparison with traditional bridge concepts. An existing composite (steel-concrete) bridge with a concrete deck that had deteriorated was selected for this purpose. Two scenarios are studied and analysed; the total replacement of the entire bridge superstructure and the replacement of the concrete deck with a new deck made of GFRP. The analyses prove that FRP decks contribute to potential cost savings over the life cycle of bridges and a reduced environmental impact.
\end{abstract}

Keywords: Bridge; Carbon emission; Composite; FRP deck; Energy consumption; Life-cycle cost; Sustainability

\section{Introduction}

Today, road authorities manage a large population of ageing bridges, a substantial number of which fail to meet the current requirements either due to deterioration and other structural deficiencies or as a result of the escalating demands imposed by increased traffic intensity and higher axle loads. As a result, the maintenance, upgrading and replacement of existing bridges have become a very challenging task for the construction industry. Complications associated with these tasks are even more critical in urban areas, where the overall cost of the project is often governed by indirect costs due to traffic disruption. New upgrading and refurbishment methods integrated with accurate urban planning which minimise the traffic disruption and disturbance in highly populated areas are therefore very useful for bridge authorities and owners.

In this context, the European PANTURA project [1] was initiated in 2011 with the emphasis on 'resource-efficient, urban-friendly bridge construction sites'. The objective of the project is to create a systematic interaction between bridge engineering and different urban planning sectors in order to improve the cost efficiency of bridge construction and minimise disturbance and the disruption of mobility. PANTURA aims to deliver integrated methods for managing flexible

\footnotetext{
${ }^{1}$ PhD student, Dept. of Civil and Environmental Engineering, Division of Structural Engineering, Chalmers University of Technology, Sven Hultins gata 8, SE - 41296 Göteborg, Sweden

${ }^{2}$ Assistant Professor, Dept. of Civil and Environmental Engineering, Division of Structural Engineering, Chalmers University of Technology, Sven Hultins gata 8, SE - 41296 Göteborg, Sweden

${ }^{3} \mathrm{PhD}$, Swedish Transport Administration, Trafikverket, Kruthusgatan 17, SE - 40533 Göteborg, Sweden
} 
construction processes, co-ordinating complex urban projects and enhanced technologies for bridge construction in urban areas. With the growing commitment of the construction industry to sustainable development, these methods should contribute to more sustainable bridge deliveries in order to achieve the goals of optimal performance, the efficient use of resources and minimum energy consumption and carbon emissions.

Within the framework of the PANTURA project, a survey was conducted to identify the demands of road authorities, bridge owners and city management offices when dealing with bridge construction activities and classify the most common problems associated with existing bridges located mainly in urban areas. The main demands imposed by road authorities and bridge owners for bridge maintenance activities and new bridge construction, based on their priority, are presented in Table 1.

Table 1 - Priorities set by road authorities and bridge owners for maintenance activities and new construction of bridges [1,2]

\begin{tabular}{l|rl}
\hline Maintenance activity & New construction \\
1) Minimisation of traffic disruption & 1) Low initial costs \\
2) Minimum application time & 2) Low maintenance costs \\
3) Low initial costs & 4) Minimise traffic disruption \\
4) High long-term performance & 5) Minimise life-cycle costs \\
5) Low maintenance costs & 6) Minimise environmental impact \\
\hline
\end{tabular}

These demands clearly indicate that sustainable industrial construction methods which lead to minimised on-site activities and construction time are promoted by the bridge industry. These methods should also lead to the minimisation of social impact and reduced initial, maintenance and life-cycle costs. In fact, several bridge authorities have already started incorporating environmentally sustainable principles in the bridge procurement process.

When it comes to the most common problems associated with existing bridges, the results of this survey indicate that the deterioration of concrete decks is one of the most pronounced problems in existing composite (steel-concrete) bridges. The replacement of deteriorated concrete decks is therefore one of the most common activities in the maintenance of existing bridges. Today, the current practice is to demolish the old, deteriorated concrete deck and replace it with a new one, which is either cast on site or assembled from precast elements. In both cases, the construction of the new bridge deck requires extensive on-site activities which lead to lengthy traffic delays.

In this respect, a potential solution which has been developed during the past decade is the application of fibre reinforced polymer (FRP) composite bridge decks. FRP decks exhibit high stiffness and strength-to-weight ratios, high fatigue and corrosion resistance and offer potential weight-saving benefits over conventional concrete decks. In addition to their light weight, the manufacturing of these decks - as prefabricated units - brings all the benefits of controlled, industrial off-site fabrication, faster transportation and rapid on-site assembly, leading to the minimisation of traffic disturbance. The application of FRP decks in a number of bridge projects has proven these advantages and demonstrated that these decks are a suitable option in deck replacement projects as well as in the construction of new bridges [3-7]. 
Despite the advantages offered by FRP decks in terms of structural performance and rapid installation, one of the obstacles to the widespread application of these decks is their fairly high initial cost. Among other viable solutions, the FRP deck option is not usually justifiable with respect to the initial cost of the project. By considering only the initial cost, the superior advantages of FRP decks are often overlooked. It is therefore important to provide a basis to demonstrate the advantages of FRP deck solutions by considering the life-time cost of the bridge and its impact on the environment and society. In this respect, life-cycle cost (LCC) and life-cycle assessment (LCA) analyses are powerful tools which could be used to demonstrate the sustainability of bridges incorporating FRP decks.

Very few studies have, however, been conducted to examine the cost efficiency and sustainability of this concept in relation to other conventional bridge concepts. The need for more studies prompted the authors to perform an assessment of the life-cycle costs and the environmental impact of two alternative solutions considered for an existing composite (steel-concrete) bridge with a deteriorated concrete deck. The total replacement of the bridge is compared with a bridge rehabilitation scenario in which the concrete deck is replaced by an FRP deck. In addition to this main aim, the paper endeavours to identify the opportunities and challenges of bridges with FRP decks with respect to important sustainability considerations, by evaluating and characterising the existing literature on this topic.

\section{Sustainability}

Sustainable development has become an increasingly important theme in many different engineering fields. The most widely used and accepted definition of sustainable development is given in the Common Future (World Commission on Environment and Development, 1987) as 'the ability to make sustainable development - to ensure that it meets the needs of the present without compromising the ability of the future generations to meet their needs'. The concept of sustainability imposes "a new way of thinking" in which the realisation of current needs should be made with regard to the environmental impact, limited natural resources and economic restraints. While the traditional design and construction of structures generally focuses on the initial cost and structural performance, sustainable design and construction adds the minimisation of the environmental impact and the cost over the entire life of structures to these demands. To this end, sustainability is related to three main interdependent aspects: (1) social development, (2) environmental protection and (3) economic development. Today, innovative technologies should be developed in an attempt to balance these aspects, i.e. to support human well-being by reducing risks and enhancing cost effectiveness and environmental benefits. To examine whether the use of FRP decks contributes to sustainable development, these three aspects of sustainability are briefly discussed.

\subsection{Social aspects}

Infrastructural projects, either in the form of new constructions or for the refurbishment of existing structures, often involve a large investment and significant social impact. The social impact can cover a broad range of indicators; however, in this paper the indicators have been limited to the ones proposed within the framework of PANTURA project [8], covering mainly the following aspects: 
- Work-zone safety on site.

- User's convenience.

- Noise and dust emissions.

Needless to say, a safe construction site is a clear and absolute requirement in any building project, not only for the workers but also for users and residents in and around the area affected by the construction. In this respect, the application of FRP bridge decks in the construction and rehabilitation of bridge structures has demonstrated several advantages, such as ease of handling and a reduced need for heavy equipment, which in turn enhance safety for workers on site [3, 5, 7, 9]. However, special considerations need to be taken into account regarding the safety of workers when they handle chemical materials such as epoxy adhesives used for deckpanel level connections or deck-girder system level connections. Adhesives can cause injury, most often through skin contact if they are handled without the necessary caution. The work should therefore be well planned in advance and protective equipment should be used.

The safety of users and residents can be measured by the number of pedestrian and traffic accidents occurring within the area affected by the construction. These accidents can be minimised by reducing the traffic restrictions around the project site (such as detours) and the total construction time. As already mentioned, FRP decks offer the benefit of accelerated construction, resulting in increased safety. The opportunity for swift construction with FRP decks also improves the user's convenience. Less delay in traffic during construction increases the comfort of users and their value of time.

Noise and dust emissions are closely related to society's welfare. In FRP bridge deck installations, the intensity of noise and vibrations is reduced due to the use of light lifting equipment on site and rapid erection. Dust emissions are also minimised thanks to the prefabrication of FRP decks and the nature of the material itself. Concrete decks can be prefabricated as well, but the dust emitted during the on-site assembly of these decks is somewhat higher in comparison with FRP decks.

\subsection{Environmental aspects}

Civil infrastructure projects, such as bridges, adversely impact the natural environment in many ways over their entire life cycle. To avoid the negative environmental impact of bridge construction and improve the sustainability, the following measures need to be taken into account:

- Reduce energy consumption.

- Reduce emissions to water, air and soil.

- Reduce waste generation/recover waste.

- Reduce virgin material usage.

Energy consumption and emissions to water, air and soil can be evaluated by following a life-cycle assessment approach. Life-cycle assessment is a framework to evaluate the environmental performance of a bridge throughout its life-cycle phases including: material acquisition/fabrication, construction, maintenance and final disposal or recycling. During these different life-cycle phases, energy is consumed and gases (e.g. carbon dioxide $\left(\mathrm{CO}_{2}\right)$, sulphur dioxide $\left(\mathrm{SO}_{2}\right)$, methane $\left(\mathrm{CH}_{4}\right)$, etc.) are released. The gas emissions contribute to different environmental impact categories 
such as: global warming potential (GWP), acidification potential (AP), eutrophication potential (EP), abiotic depletion potential (ADP), ozone depletion potential (ODP), ecotoxicity (ETC), and human toxicity (HTC). Due to lack of space, in this study, focus is laid on carbon dioxide emissions which are mainly connected to the impact category of global warming potential.

The main sources of energy and carbon dioxide emissions during the life cycle of a bridge can be identified during the following activities:

- Material extraction and production.

- Transportation of materials/waste/employees during the construction, maintenance and disposal phases.

- On-site activities and construction equipment use during construction and demolition.

- Traffic congestion and detours during construction and maintenance activities.

- Possible energy recovery from recycling materials in the disposal phase.

As noted, the input data for conducting a life-cycle assessment for a bridge are extensive and complex calculations are involved. It is difficult to obtain all this information for bridge projects, especially in the procurement stage, because the required data are less readily available, accurate and complete, which in turn leads to many assumptions and simplifications during the assessment. It is therefore important to keep life-cycle assessments as transparent and comprehensive as possible. So far, limited life-cycle assessment studies have produced promising results relating to the environmental impact of FRP materials in bridges. It should be recognised that considerations may vary substantially for different types of work, such as the upgrading of existing bridges or newly built bridges. For instance, energy use and carbon emissions from traffic congestion and diversions might play a significant role in the upgrading of existing bridges, whereas the embodied energy and carbon footprint of the construction materials might be dominant for the construction of new bridges.

\subsubsection{Energy consumption}

The first stage of the life-cycle phase of any product is the material acquisition and fabrication which accounts for the major part of energy consumption. The energy consumed by the production of fibre-reinforced materials, also referred to as materialembodied energy, can vary significantly according to the type of fibres and the manufacturing processes (see Figure 1). Fibre-reinforced polymer decks usually comprise glass fibres, which require substantially lower energy consumption compared with carbon fibres, see Figure 1. 


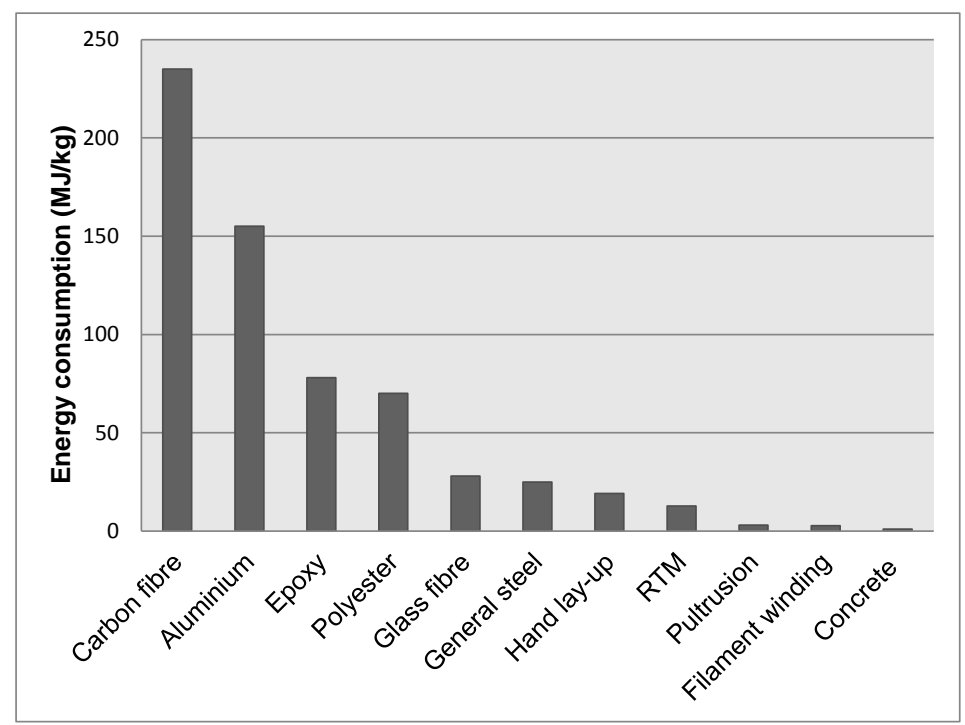

Figure 1 - Energy consumption for production of different materials and manufacturing processes [10, 11]

It should naturally be borne in mind that, while evaluating the environmental impact of a material, the quantity and the functions of the materials need to be available. For instance, even though the embodied energy consumption for concrete is less than that for glass fibre reinforced polymer (GFRP) material, the quantity of GFRP material used for a bridge deck is less than that for a concrete deck.

Daniel [12] demonstrated the environmental advantage of composite materials in terms of energy consumption, compared with four other materials, namely structural steel, stainless steel, aluminium and reinforced concrete, for a two-span, simplysupported pedestrian bridge. The results indicated that a composite FRP bridge made of pultruded GFRP elements requires the least energy compared with bridges made of other materials. In this study, the embodied material energy consumption during both the construction and maintenance stages was included. In addition, Daniel [12] compared water and air pollution generated during the production of FRP components to that obtained with other materials; structural steel, aluminium and reinforced concrete. The results show that the composite bridge is best in terms of the resulting water and air pollution levels.

Another energy consumption study of a 12-metre road bridge was performed by the BECO Group [13]. A bridge superstructure made of composite materials (glass fibre reinforced and carbon fibre reinforced polymer material) was compared with alternative solutions incorporating traditional materials (steel and concrete). The substructure of the bridge was made of concrete in all cases. The results revealed that a substantial saving in energy consumption can be obtained when the bridge superstructure is made of glass fibre polymer materials (see Figure 2). 


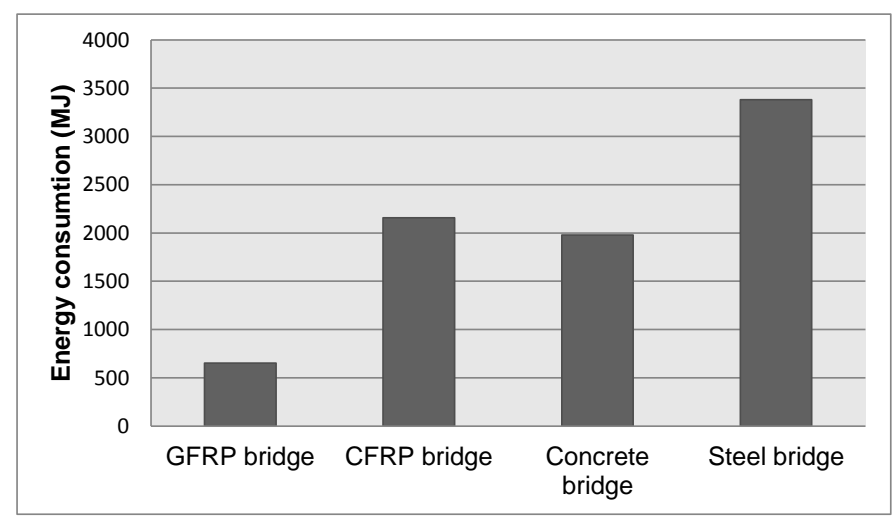

Figure 2 - Comparison of energy consumption of a road bridge composed of various material options (input data: [13])

In BECO's study, the following assumptions were made in the analysis: (i) the bridge life span is set at 50 years, (ii) no maintenance is required for the composite bridge alternative during the bridge service life, (iii) re-use of composite bridges after 50 years and (iv) incineration with energy recovery for the composite materials where $16,700 \mathrm{KJ}$ per tonne of heat energy would be recovered. Although these assumptions could be disputed, the difference in energy consumption for the GFRP bridge is very pronounced compared with concrete and steel bridges, demonstrating the advantage of bridges composed of GFRP materials. The decrease in energy consumption for composite bridges is also attributed to the material savings in the concrete substructure owing to the light weight of FRP materials.

\subsubsection{Carbon emissions}

The production of FRP materials generates a higher unit amount of carbon emissions when compared with other conventional materials such as concrete or steel. Despite the high unit amount of carbon emissions during the production phase, several lifecycle assessments have shown that carbon emission savings can be obtained when other factors during the construction, maintenance or disposal stages are considered. Tanaka et al. [14] demonstrated that the carbon emissions of an FRP footbridge can be reduced by $26 \%$ compared with a pre-stressed concrete (PC) footbridge. The carbon emission savings were attributed to the reduction in material needed for the substructure due to the light weight of FRP material and also to the transportation method used for FRP elements. In this study, the FRP elements were assumed to be delivered by marine transportation which yielded far fewer carbon emissions compared with land transportation, which would normally be the alternative for a PC footbridge. Another study performed by the BECO Group [13] showed that the carbon emissions for a $12 \mathrm{~m}$ long road bridge composed of a GFRP composite superstructure were reduced by $48 \%$ compared with a concrete bridge (see Figure 3 ). 


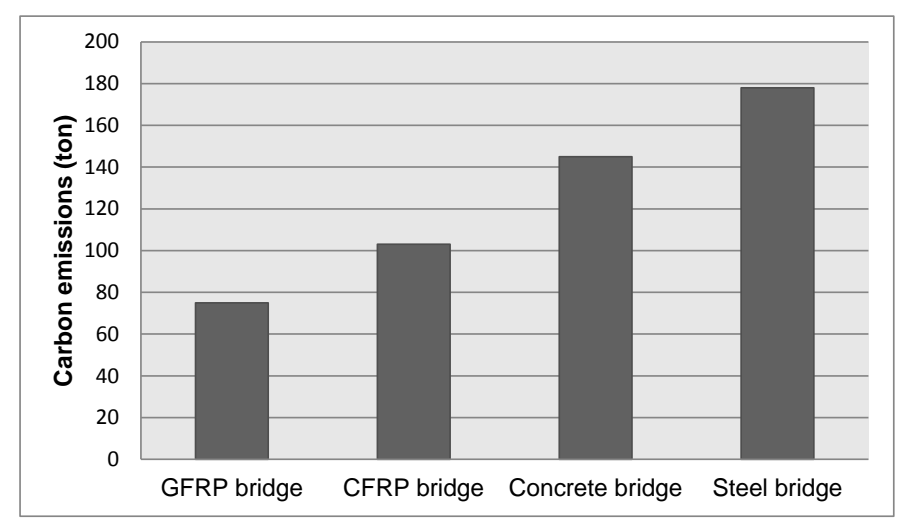

Figure 3 - Comparison of carbon emissions for four bridges composed of different materials

Zhang et al. [15] compared life-cycle carbon emissions for an FRP deck replacement project versus a conventional concrete deck in a 12-metre, single-span road bridge. The comparison showed that traffic diversions contributed significantly to carbon emissions during the deck replacement stage. The FRP deck option resulted in fewer carbon emissions than the concrete deck option, mainly due to faster installation and thereby fewer traffic diversions. However, during the maintenance stage, an increase in carbon emissions was seen for the FRP deck option. This was attributed to the maintenance of the polymer concrete which was regarded as the surfacing material for the FRP deck. Polymer concrete has much higher embodied-material carbon emissions than conventional surfacing materials such as asphalt. In all, the accumulation of carbon emissions over the theoretical service life of 120 years for the FRP deck option resulted in approximately $13 \%$ higher emissions than the concrete deck option. According to this study, the results show that the FRP bridge decking option is competitive in comparison with concrete decks, but there is room for improvement regarding the wear surface used for FRP decks.

\subsubsection{Waste management}

The management of waste is another key component of environmental sustainability. The concept of a waste hierarchy, which is the nucleus of waste minimisation strategies, is defined as:

1) Waste prevention or reduction.

2) Re-use.

3) Material recycling.

4) Energy recovery.

5) Landfill/disposal.

In this waste hierarchy, waste prevention/reduction and the re-use of waste materials are the most preferred options for waste management. FRP decks are pre-fabricated using different manufacturing processes, which are usually very efficient and result in waste minimisation. In addition, owing to the nature of prefabrication, the generated on-site waste is kept to a minimum. However, the re-use of remaining FRP elements during manufacture or construction is fairly limited, because the production is done for specific purposes. From another point of view, minimising material usage is the best option for avoiding frequent maintenance and repair needs. In this regard, 
replacing the deteriorated existing decks with FRP decks to extend the service life and building new bridges with FRP decks to achieve a longer service life with minimum maintenance minimises the use of materials.

The recycling of materials is essential for sustainability. It facilitates the minimum use of virgin materials for different products. Today, the production of FRP decks, which comprise glass fibres and thermosetting polymers, is performed using $100 \%$ virgin materials. Glass fibres are mainly made from quartz powder and limestone, which are practically unlimited natural and environmentally sustainable resources. The polymers are derived from by-products from the oil industry [16] - which have a significant impact on the environment - but the amount used in the production of FRP decks is comparatively low with respect to the fibre contents. The reason for using $100 \%$ virgin materials for the production of FRP decks is not that FRP composites cannot be recycled, but that the recycled FRP material is not appropriate for use in structural FRP decks. The recycling of FRP composites can be done in several ways. One option is to crush and granulate the material, which can be used as filler or reinforcing material in composite materials or other products. Another method called chemical recycling is applied to dissolve the resin and fibres, which allows the former components to be re-used in other composite products. An alternative method to chemical recycling is thermal recycling, which performs the same functions.

The incineration of composites with energy recovery is a potential sustainable method for FRP waste management. Composite materials release a large amount of energy in controlled incineration, which makes them energy carriers for heating or electricity. The remains after incineration are glass fibres which can be used for manufacturing glass wool. One problem encountered during the incineration of FRP composites is overloading the incineration system due to high calorific power and toxic emissions [17]. This problem compromises the advantages of FRP materials as energy carriers. It is therefore important to consider the negative impact of toxic emissions while counting on energy recovery. The incineration of composites in cement kilns to replace some of the clay and limestone fillers for the cement is another suggested method for the waste management of composites. The proportion of replacement material should be limited to some extent in order not to affect the primary functions of cement. Even though there are different sustainable ways of dealing with FRP waste, they are still in their infancy and are not in regular use, making the landfill method a common solution for managing FRP waste.

\subsection{Economic aspects}

In today's world, economic viability is an important consideration for the infrastructure industry due to limited resources. From a short-term perspective, new technologies such as FRP decks might seem unattractive due to high initial costs. However, there are costs beyond the initial costs that should be considered in the cost estimation of bridges. Life-cycle cost analysis (LCC) is a good evaluation method for assessing the economic viability of bridges. LCC analysis takes account of construction costs, operation/maintenance/repair costs, end-of-life costs, social costs and environmental costs. Social costs comprise user delay costs, vehicle operation costs and accident costs [18]. In bridge applications in densely populated areas, these costs can account for up to $90 \%$ of the total bridge costs [19]. LCC analyses of bridges utilising FRP decks are scarce in the literature and they are often based on assumptions, making it difficult to make a true comparison. Nevertheless, several 
conclusions can be drawn based on the LCC analyses in the literature. One of the main benefits of FRP decks is the savings in social costs during construction and replacement activities, making FRP bridge decks more economical than concrete decks $[18,20]$. FRP decks can thus be a life-cycle cost-effective alternative to conventional concrete decks, particularly for bridges located in urban areas with high traffic intensity, as demonstrated by Nystrom et al. [21]. Other than savings on social costs, the swift construction and light weight of FRP decks allow a reduction in installation labour costs, equipment costs and traffic management costs during construction. The light weight of FRP decks offers additional cost savings for the structure to support the deck (such as girders and piers). Nishizaki et al. [22] observed $32 \%$ cost savings for the substructure of an FRP pedestrian bridge compared with the alternative of a pre-stressed concrete footbridge. For the construction of the world's largest FRP composite-deck bridge, the Noolcha Bridge in Korea [6], the initial construction costs were considerably reduced, due to the low weight of the composite deck, allowing for a reduction in the necessary number of marine pile foundations to support the deck. Substantial project cost savings can also be obtained by rehabilitating a functionally obsolete bridge with an FRP deck instead of replacing the entire bridge.

One concern when it comes to life-cycle cost analyses of FRP decks is the uncertainty associated with maintenance costs, since the long-term performance of these decks is not well known and available data can be contradictory. Researchers usually assume lower maintenance costs for FRP decks compared with concrete decks, but in some cases the opposite is assumed [18]. To date, field experience of FRP bridge deck applications has shown that the main concern is cracking of the overlay and not the FRP deck itself [23]. If a better option for the wear surface of FRP decks is developed, a certain degree of cost repair reduction can be obtained.

\section{Case-study bridge}

In order to arrive at a quantitative assessment of the sustainability of bridge concepts incorporating FRP bridge decks, a comparative analysis needs to be performed on a well-defined case. For this purpose, a case-study bridge was selected and analysed with regard to life-cycle costs and environmental impact in terms of carbon emissions. However, before any general conclusions can be drawn, a wide range of bridge types and spans should be studied by performing such analyses. The conclusions from the case-study bridge considered in this paper should therefore not be generalised.

The bridge considered in this study was built in 1948 in the north of Sweden over a small watercourse called Rokån. The bridge was simply supported, spanning 12 metres, with a free width of 6 metres carrying two lanes of traffic. The bridge superstructure consisted of a reinforced concrete deck resting on two steel girders with no intended composite action (see Figure 4). An assessment of the bridge made in 2002 showed that it was in need of rehabilitation due to the deterioration of the concrete deck. There was also a need to widen the bridge deck by one metre. The steel girders were generally in good condition (no corrosion or fatigue problems were encountered) but were judged to have an insufficient load-carrying capacity with respect to current traffic loads. In dealing with the problem - whether through an upgrading or a total replacement of the bridge - the road authorities requested a minimum disruption of the traffic on the connected road network. The final decision taken by the road authorities was to replace the entire superstructure of the bridge 
with a new superstructure consisting of a prefabricated concrete deck acting compositely with two steel girders. This new superstructure was assembled on site beside the old bridge in 35 days. After assembly, the old superstructure of the bridge was demolished and replaced by the new superstructure. During the bridge replacement process, the bridge was closed for 30 hours and the traffic flow was diverted to an alternative route which was $16 \mathrm{~km}$ longer than the original one [24].

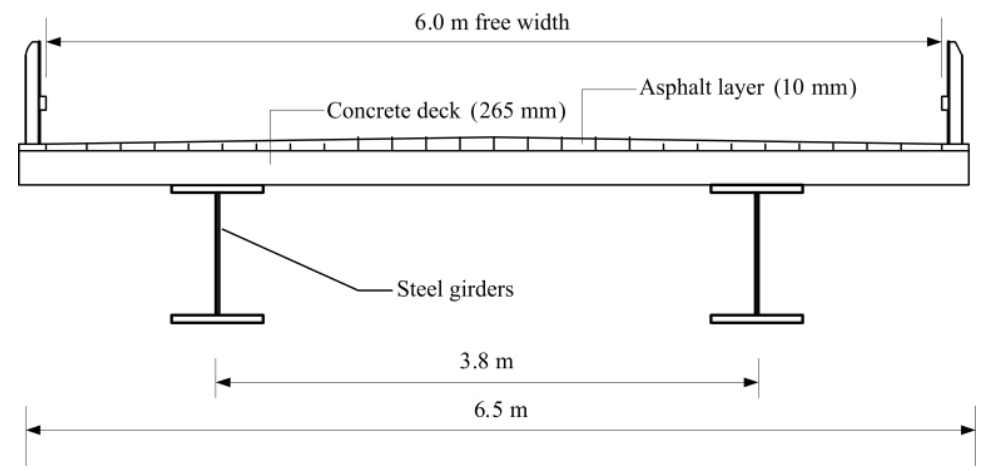

Figure 4 - Cross-section of the old Rokån bridge

Replacing the old concrete deck with a new one was not an option. Due to the high weight of the concrete deck, the load-carrying capacity of the bridge would still have been limited by the capacity of the steel girders.

Another potential solution would have been to replace the deteriorated concrete deck with an FRP deck. The steel girders were still in good condition and the lightweight FRP deck would only induce marginal load effects in the girders. This would in turn allow for an increase in live traffic loads. An analysis of this upgrading option was made by Mara [25]. The results show that the minimum performance-based requirements (such as load-carrying capacity, deflection and fatigue strength) would all be met by this alternative.

To replace the deck with a new FRP deck, the required bridge closure time includes the time needed to demolish the old concrete deck and install the new FRP deck. Demolishing the old concrete deck in the old bridge took three hours (personal contact with Ramböll AB, Sweden). The time needed to install the new FRP deck is assumed to be 12 hours, which is based on previous experience of FRP deck installations (personal contact with Fiberline Composites, Denmark). The total bridge closure time for replacing the deck is therefore estimated to be approximately 15 hours - i.e. half the closure time needed for the bridge replacement performed in 2002.

In this study, these two upgrading alternatives are compared based on a life-cycle cost analysis and a study of the environmental impact in terms of carbon emissions. In the following text, Alternative 1 will be used to refer to the upgrading scenario with a total replacement of the bridge superstructure as in the real project, while Alternative 2 refers to the alternative where the old concrete deck is replaced with an FRP deck.

\subsection{Life-cycle cost analysis}

In this study, the life-cycle cost analyses for both alternatives are based on initial construction costs, maintenance/repair/replacement costs, associated social costs, environmental costs and end-of-life costs. The bridge is considered to have a design life span of 80 years. The main construction and assumed maintenance activities during the life span of the bridge are presented in Table 2. After the initial 
construction, it is assumed that the maintenance activities will be limited solely to the deck. This assumption makes the comparison between different options easier and it is realistic, as the other bridge components undergo the same maintenance activities in both cases. However, painting of the steel girders is added in the initial construction activities of alternative 2, since the steel girders are reused. The assumptions presented in Table 2 are made by consulting a number of professionals about maintenance activities in Sweden.

Table 2 - Overview of the construction and maintenance activities for both alternatives

\begin{tabular}{|c|c|c|c|c|c|}
\hline \multicolumn{6}{|c|}{ Alternative 1 (bridge replacement) } \\
\hline \multicolumn{2}{|c|}{ Construction activity } & Frequency & \multirow{2}{*}{\begin{tabular}{|l} 
Description \\
$\begin{array}{l}\text { Replacement of the old } \\
\text { superstructure }\end{array}$
\end{tabular}} & \multirow{2}{*}{\begin{tabular}{|l|} 
Duration \\
30 hours \\
\end{tabular}} & \multirow{2}{*}{$\begin{array}{l}\begin{array}{l}\text { Traffic } \\
\text { disturb } \\
\text { ance }\end{array} \\
\text { All } \\
\text { lanes } \\
\text { closed }\end{array}$} \\
\hline Initial & $\begin{array}{l}\text { Replacement of } \\
\text { the superstructure }\end{array}$ & Once & & & \\
\hline \multirow{2}{*}{ Future } & $\begin{array}{l}\text { Surface } \\
\text { maintenance }\end{array}$ & $\begin{array}{ll}\text { Every } & 10 \\
\text { years } & \end{array}$ & $\begin{array}{l}\text { Removal and } \\
\text { replacement of the } \\
\text { asphalt }\end{array}$ & 24 hours & $\begin{array}{l}1 \text { closed } \\
\text { lane }\end{array}$ \\
\hline & $\begin{array}{l}\text { Replacement of } \\
\text { insulation } \\
\text { (waterproofing) }\end{array}$ & $\begin{array}{ll}\text { Every } & 40 \\
\text { years } & \end{array}$ & $\begin{array}{l}\text { Removal and } \\
\text { replacement of the } \\
\text { insulation } \\
\text { (waterproofing) }\end{array}$ & 2 weeks & $\begin{array}{l}1 \text { closed } \\
\text { lane }\end{array}$ \\
\hline \multicolumn{6}{|c|}{ Alternative 2 (deck replacement with an FRP deck) } \\
\hline \multirow{2}{*}{ Initial } & $\begin{array}{l}\text { Replacement of } \\
\text { the deck }\end{array}$ & Once & $\begin{array}{l}\text { Replacement of } \\
\text { concrete deck with a } \\
\text { FRP deck }\end{array}$ & 15 hours & $\begin{array}{l}\text { All } \\
\text { lanes } \\
\text { closed }\end{array}$ \\
\hline & $\begin{array}{l}\text { Painting of the } \\
\text { steel structure }\end{array}$ & Once & $\begin{array}{l}\text { Painting of the steel } \\
\text { girders }\end{array}$ & 15 hours & $\begin{array}{l}\text { All } \\
\text { lanes } \\
\text { closed }\end{array}$ \\
\hline Future & $\begin{array}{l}\text { Surface } \\
\text { maintenance }\end{array}$ & $\begin{array}{ll}\text { Every } & 20 \\
\text { years }\end{array}$ & $\begin{array}{l}\text { Removal and } \\
\text { replacement of the } \\
\text { polymer concrete }\end{array}$ & 24 hours & $\begin{array}{l}1 \text { closed } \\
\text { lane }\end{array}$ \\
\hline
\end{tabular}

\subsubsection{Initial construction costs}

The initial construction costs include material and manufacturing costs, installation costs (labour, equipment use) and transportation costs. The total initial construction costs for the bridge replacement alternative have been obtained from the contractor involved in the project in 2002 [24]. These costs have been adjusted to the present value by assuming an inflation rate of $i=4 \%$ [26] using the following equation:

$C_{T}=C_{t} \cdot(1+i)^{t}$ 
where $\mathrm{i}=$ inflation rate; $\mathrm{C}_{\mathrm{t}}=$ costs incurred at time $\mathrm{t}, \mathrm{C}_{\mathrm{T}}=$ present cost.

The cost of the FRP deck option has been obtained from the FRP deck fabricator, Fiberline Composites [27] (see Table 3).

Table 3 - Project cost parameters

\begin{tabular}{|l|l|l|}
\hline Item & $\begin{array}{l}\text { Prefabricated } \\
\text { concrete deck }\end{array}$ & FRP deck \\
\hline Cost of the deck $($ euro/m²) & 522 & 805 \\
\hline Thickness of wear surface (mm) & 90 & 30 \\
\hline $\begin{array}{l}\text { Cost of wear surface including } \\
\left.\text { surfacing (euro/ } \mathrm{m}^{2}\right)\end{array}$ & 42 & 105 \\
\hline Cost of steel painting (euro/m $\left.{ }^{2}\right)$ & - & 200 \\
\hline
\end{tabular}

\subsubsection{Maintenance and repair costs}

Maintenance and repair costs have been calculated taking account of the future activities presented in Table 2. These estimated costs are based on data from the bridge contractor in the original project and the repair costs in the Swedish BatMan database [28]. BaTMan stands for Bridge and Tunnel Management system and is an internet-based software containing information about bridges in Sweden, the oldest bridges dating back to 1944 . All these future costs have been converted to the present value with a discount rate of $4 \%$ and have been added up to yield the life-cycle costs as in the following equation:

$$
L C C_{T}=\sum_{n=1}^{k} \frac{C_{t}}{(1+d)^{t}}
$$

where $\mathrm{d}=$ discount rate; $\mathrm{C}_{\mathrm{t}}=$ costs incurred at time $\mathrm{t} ; \mathrm{LCC}_{\mathrm{T}}=$ present life-cycle cost.

\subsubsection{Social and environmental costs}

The social costs are associated with traffic disturbances which occur during the initial construction and during the maintenance activities as presented in Table 2 . In this study, the social costs include driver delay and vehicle operating costs. The accident costs are not taken into account due to the lack of data. The driver delay costs and the vehicle operating costs depend on the additional time drivers spend on detours and are calculated based on the equations provided by Ehlen [18].

The input data to estimate the social cost of both alternatives during the initial construction phase are given in Table 4. The average daily traffic rate is assumed to remain constant throughout the assumed life span of the bridge. In the bridge replacement case, the traffic speed was limited in different time spans during the assembly of the new superstructure beside the old bridge. This traffic speed limit contributes to additional social costs, which is not the case when replacing the deck with an FRP deck. 
Table 4 - Input data for social cost analysis during initial construction [24]

\begin{tabular}{|l|l|l|}
\hline Item & Alternative 1 & Alternative 2 \\
\hline Average daily traffic (ADT) & 796 vehicles/day & 796 vehicles/day \\
\hline $\begin{array}{l}\text { Time loss of drivers due to detour } \\
\text { during closure of the bridge }\end{array}$ & 15 minutes & 15 minutes \\
\hline Hours of closure of the bridge & 30 hours & 15 hours \\
\hline Hourly time value of drivers & $28 € / \mathrm{h}$ & $28 € / \mathrm{h}$ \\
\hline Hourly vehicle operating cost & $21 € / \mathrm{h}$ & $21 € / \mathrm{h}$ \\
\hline Normal traffic speed & $90 \mathrm{~km} / \mathrm{h}$ & $90 \mathrm{~km} / \mathrm{h}$ \\
\hline $\begin{array}{l}\text { Traffic speed during assembly of } \\
\text { the superstructure for } 14 \text { days }\end{array}$ & $70 \mathrm{~km} / \mathrm{h}$ & - \\
\hline $\begin{array}{l}\text { Traffic speed during assembly of } \\
\text { the superstructure for } 7 \text { days }\end{array}$ & $50 \mathrm{~km} / \mathrm{h}$ & - \\
\hline Length of the affected roadway & $200 \mathrm{~m}$ & - \\
\hline
\end{tabular}

During maintenance activities, the traffic speed is assumed to be limited to $70 \mathrm{~km} / \mathrm{h}$, compared with a normal driving speed of $90 \mathrm{~km} / \mathrm{h}$. The affected road length (working zone) is presumed to be the bridge deck length $(12 \mathrm{~m})$ plus 15 metres on each side. In addition to the time loss due to limited traffic speed, an extra delay of 10 seconds is added for traffic queues caused by the closure of one lane, as presented in Table 2.

The environmental costs estimate the damage costs for pollutants and greenhouse gas emissions during the assumed life span of a bridge. In this study, only the environmental costs associated with $\mathrm{CO}_{2}$ emission damage due to material processing, transportation and traffic diversions (detailed analyses in Section 3.2) are included. The unit damage cost for a metric tonne of $\mathrm{CO}_{2}$ has been obtained from Chandler [29] and converted to the present value as 6.64 euro/tonne.

\subsubsection{Disposal costs}

Disposal costs occur at the end of the life of structures. In this study, the disposal of concrete is assumed to be diverted to landfill at a fee of 110 euro/tonne, while the steel material is recycled and has a profit of 50 euro/tonne (ref. Ramböll AB, Sweden). FRP materials are assumed to be sent to a recycling plant where a fee of 110 euro/tonne is paid (ref. Fiberline Composites, Sweden).

\subsubsection{Total life-cycle costs}

The estimated total costs for each alternative are summarised with cost breakdowns in Table 5. The first category displays the costs during the different life-cycle phases of the bridge, whereas the second level displays the costs according to cost entities. Agency costs include financial costs associated with the materials, construction, 
maintenance and end-of-life stages. It is worth noting that, for both categories, the sum of the costs is the same. The results show that the total life-cycle cost of the deck replacement alternative is $31 \%$ lower than the first bridge replacement alternative. Looking at the cost breakdowns, all the costs for Alternative 1 are higher than for Alternative 2.

For this particular bridge, it is observed that social and environmental costs comprise under $8 \%$ of the total costs. This is due to the fact that the bridge is located in a rural area with fairly low average daily traffic. Moreover, the construction time for both alternatives is relatively short and the social costs are heavily dependent on the bridge closure time. The deck replacement alternative results in 53\% lower social costs compared with Alternative 1, which is due to more rapid construction and fewer maintenance activities which influence the traffic.

The end-of-life costs are significantly less for the deck replacement alternative, since demolition of the concrete deck requires heavy equipment, while FRP decks require significantly less time and effort.

Table 5 - Total life-cycle costs (all units in euro)

\begin{tabular}{|l|l|l|}
\hline Cost category & Alternative 1 & Alternative 2 \\
\hline 1 - By life-cycle phase & & \\
\hdashline Initial costs & 165,153 & 123,312 \\
\hline Maintenance and repair costs & 26,920 & 9,697 \\
\hline End-of-life costs & 893 & 193 \\
\hline Total costs & $\mathbf{1 9 2 , 9 6 6}$ & $\mathbf{1 3 3 , 2 0 2}$ \\
\hline 2- By cost entity & & \\
\hline Agency costs & 178,799 & 126,561 \\
\hline Social and environmental costs & 14,167 & 6,641 \\
\hline Total costs & $\mathbf{1 9 2 , 9 6 6}$ & $\mathbf{1 3 3 , 2 0 2}$ \\
\hline
\end{tabular}

\subsubsection{Sensitivity analysis}

Life-cycle cost analyses are sensitive to several individual project parameters, particularly social costs related to traffic conditions. In this case study, the bridge is located in a rural area with a really low traffic volume. With regard to the PANTURA project, it is interesting to study the effect of the average daily traffic (ADT) volume on the bridge on the results of the life-cycle cost analysis. A sensitivity analysis is therefore performed by varying the ADT on the bridge, see Figure 5. The costs are presented according to the cost entity: agency costs and social (including environmental) costs through the life cycle of the bridge. It is only the social costs that vary with ADT, whereas the construction costs remain the same for both cases. Social costs increase with increasing ADT and they start to dominate the total life-cycle costs starting from average daily traffic of about 10,000 vehicles/day. It is observed that, in 
the case of ADT $=20,000$ vehicles/day, the social costs of the prefabricated concrete deck bridge option exceed the total life-cycle costs of the FRP deck bridge alternative. This example clearly demonstrates that bridges with FRP decks are more cost efficient than traditional bridges, especially in areas with high traffic volumes.

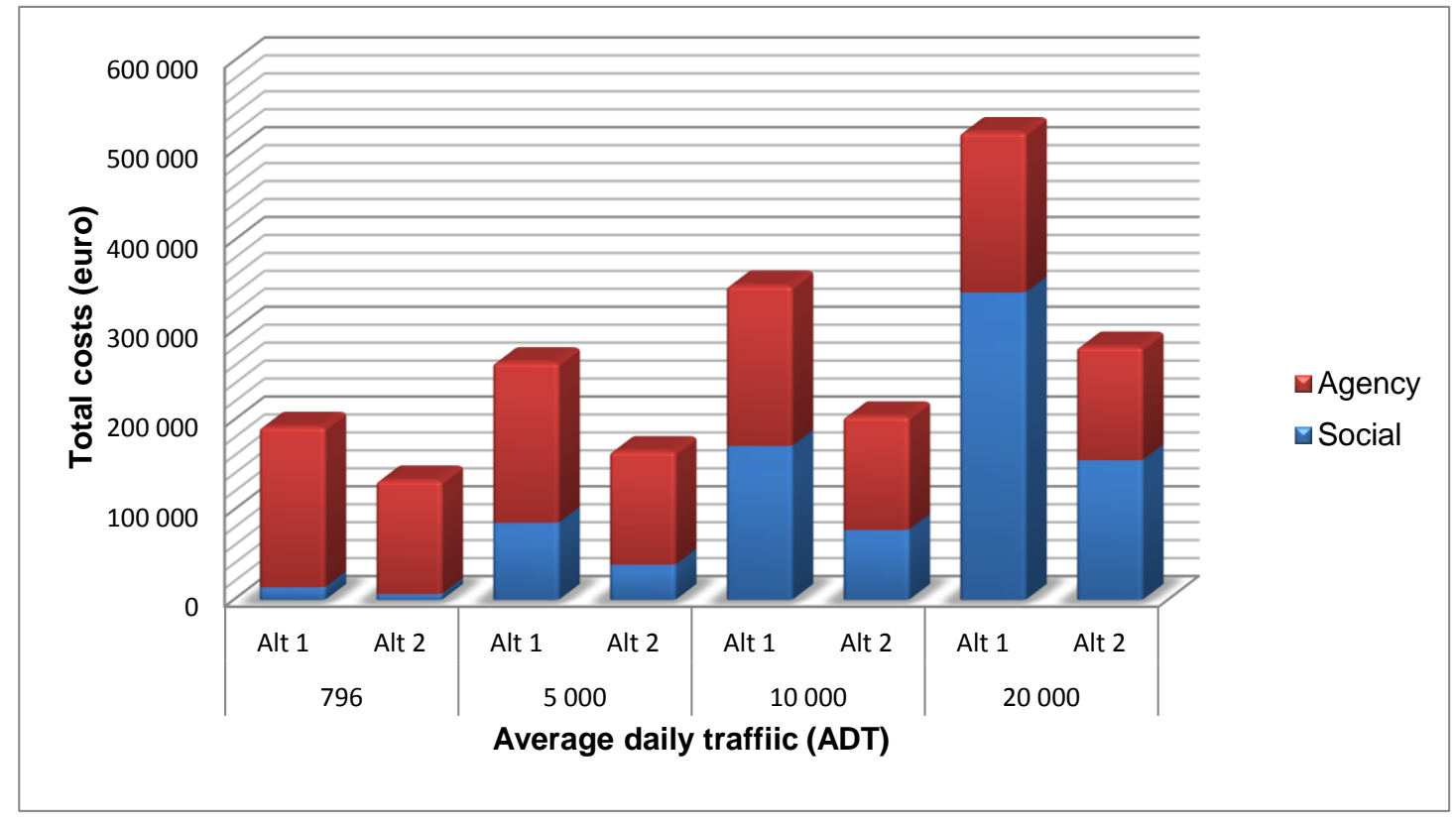

Figure 5 - Effect of the average daily traffic volume on the life-cycle costs of both bridge alternatives

\subsection{Environmental impact}

\subsubsection{Introduction and input data}

In this study, the environmental impact is investigated in terms of only carbon emissions throughout the life cycle of the two bridge alternatives. The main sources of carbon emissions are related to: (i) material production, (ii) material/waste transportation and (iii) traffic detours. Other sources of carbon emissions such as those generated by construction equipment are not included in this study due to lack of information.

The unit carbon emissions for material, transportation and vehicle operation used in this study are presented in Table 6. The embodied material carbon emissions are mostly based on the Inventory of Carbon and Energy [11]. The unit-embodied carbon emission value of FRP material is slightly modified, since the only available reference in the ICE database dates from 1998. The continuous development and widespread application of FRP materials has led to lower unit-embodied carbon emission values, which in other studies is quoted to vary from 3 to $5 \mathrm{kgCO}_{2} / \mathrm{kg}$ [30]. The embodied carbon emission of polymer concrete is based on a weight ratio of 1:4 of epoxy resin to aggregate [15]. The material quantities taken into consideration for the analyses are those used for main structural elements. Non-structural elements (such as parapets) are not included, as they are assumed to be the same for both bridge cases.

The unit amount of carbon emissions for transportation and vehicle operation are taken as the values proposed by the Environmental Agency in London [31]. Transportation includes road and water transportation, as the FRP deck is assumed to be transported from Denmark by ship. Road transportation of the prefabricated 
elements from the factory to the site is considered to be approximately $100 \mathrm{~km}$, while water transportation is assumed to be $300 \mathrm{~km}$. The transportation distance for the waste material during demolition stages is assumed to be $20 \mathrm{~km}$.

Table 6 - Unit material carbon emission amounts [11, 31]

\begin{tabular}{|c|c|c|c|}
\hline \multicolumn{2}{|l|}{ Heading } & Unit & Unit amount of $\mathrm{CO}_{2}$ emissions \\
\hline \multirow{10}{*}{ Materials } & Prefabricated concrete & \multirow{9}{*}{$\mathrm{kgCO}_{2} / \mathrm{kg}$} & 0.215 \\
\hline & Reinforcement steel & & 1.71 \\
\hline & Steel & & 1.77 \\
\hline & Asphalt & & 0.14 \\
\hline & FRP & & 5 \\
\hline & Aggregate & & 0.005 \\
\hline & Epoxy resin & & 5.91 \\
\hline & Polymer concrete & & 1.18 \\
\hline & Insulation & & 2.5 \\
\hline & Paint & $\mathrm{kgCO}_{2} / \mathrm{m}^{2}$ & 0.53 \\
\hline \multirow{2}{*}{ Transportation } & Road & \multirow{2}{*}{$\begin{array}{l}\mathrm{kgCO}_{2} / \mathrm{t} \\
\mathrm{km}\end{array}$} & 0.1067 \\
\hline & Water & & 0.015 \\
\hline Vehicle & General & $\mathrm{gCO}_{2} / \mathrm{km}$ & 300 \\
\hline
\end{tabular}

Another source of carbon emissions is associated with the traffic disruption during construction and maintenance work. Carbon emissions due to traffic detours depend on daily traffic volume, detour distance and the period of disruption (bridge closure). To calculate the carbon emissions from traffic disruption, the same traffic input data presented in Section 3.1.3 are used.

\subsubsection{Carbon emission results}

A detailed breakdown of carbon emissions during different life-cycle phases of the bridge is presented in Table 7. In overall terms, the bridge with an FRP deck is more favourable, as it generates approximately $20 \%$ fewer carbon emissions compared with the bridge with a prefabricated concrete deck.

It is worth noting that, for both alternatives, the embodied material carbon emissions contribute to the majority of total carbon emissions. In the initial construction phase, the difference in embodied material carbon emissions between the two alternatives is not that pronounced, which reflects the high unit carbon value of FRP decks. The same applies during the maintenance and repair phase, which is attributed to the higher carbon emission level for the maintenance of the polymer concrete material, used as an overlay for the FRP deck. Polymer concrete generates high materialembodied carbon emissions, thereby resulting in higher carbon emissions than Alternative 1, even though the maintenance frequency is assumed to be lower for Alternative 2. 
Carbon emissions from transportation are considerably lower for the second alternative due to the water transportation of the FRP deck, but the contribution of these emissions to the total emissions is almost negligible for both alternatives.

Table 7 - Total carbon emissions of both alternatives (all units in $\mathrm{kgCO}_{2}$ )

\begin{tabular}{|l|l|l|}
\hline Life-cycle phases & Alternative 1 & Alternative 2 \\
\hline Initial construction & \multicolumn{2}{|l|}{} \\
\hline Material & 57,667 & 48,158 \\
\hline Transportation & 1,354 & 172 \\
\hline Traffic detours & 4,776 & 2,388 \\
\hline Total & $\mathbf{6 3 , 7 9 7}$ & $\mathbf{5 0 , 7 1 8}$ \\
\hline Maintenance and repair & & \\
\hline Material & 23,047 & 21,001 \\
\hline Transportation & 2,104 & 228 \\
\hline Traffic detours & $\mathbf{9 3 8}$ & 63 \\
\hline Total & $\mathbf{2 6 , 0 8 9}$ & $\mathbf{2 1 , 2 9 2}$ \\
\hline End of life & & \\
\hline Transportation & 246 & $\mathbf{2 2 , 0 5 9}$ \\
\hline Total carbon emissions & $\mathbf{9 0 , 1 3 2}$ & \\
\hline
\end{tabular}

Carbon emissions generated by traffic detours comprise a very small percentage of the total carbon emissions for both alternatives. These carbon emissions are closely related to bridge closure time and average daily traffic volume. This bridge is located in a rural area and a parametric study was therefore undertaken to study the impact of the average daily traffic on carbon emissions. By keeping all the other factors constant, the traffic volume is changed to 20,000 and the results are compared with the original traffic volume of 796 vehicles/day (see Figure 6). 


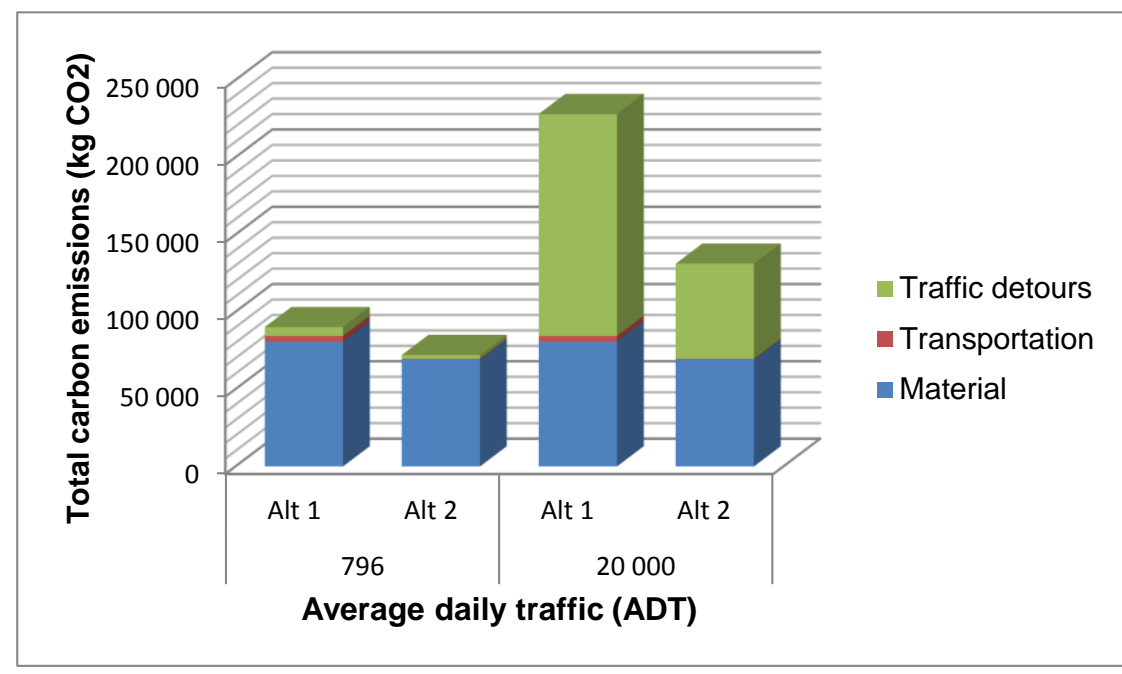

Figure 6 - Effect of average daily traffic on total carbon emissions for both alternatives

It is clear from the results in Figure 6 that carbon emissions from traffic detours dominate with increased average daily traffic (ADT). For the bridge replacement alternative, this contribution changes from $6 \%$ to $63 \%$ of the total carbon emissions, thereby reflecting the longer construction period and traffic disruption for this option. The bridge with an FRP deck results in a more pronounced environmentally sustainable option in areas with higher traffic volumes.

\subsection{Discussion of the results}

The presented example illustrates the advantages of using FRP decks in bridge deck replacement projects instead of replacing the entire superstructure. This holds true in terms of both costs and environmental impact, when this option naturally fulfils the technical requirements. In addition, the social impact of the bridge with an FRP deck is reduced due to a shorter construction period, resulting in fewer traffic delays, less air pollution generated by traffic and construction equipment and a safer working zone. Quick construction also implies fewer social costs and carbon emissions due to traffic detours, as verified in this study.

It should be mentioned that, in this case study, there is some uncertainty about the unit values of embodied-material carbon emissions, especially for the FRP material and polymer concrete. This creates some degree of uncertainty in the results, which are very sensitive to these input data. In the case of FRP decks, polymer concrete material used as an overlay makes a major contribution to carbon emissions. If asphalt were considered as an overlay, a further reduction of $17 \%$ in total carbon footprint would be achieved for the deck replacement alternative. The analysis also confirms that the environmental impact is dependent on several factors (e.g. traffic diversions, transportation, and material) and the results are accordingly very sensitive to these parameters. This proves the need for life-cycle assessments for various bridge projects in order to identify the best solution since, in a sense, each bridge is unique.

It should also be noted that, in this study, the environmental impact is limited by addressing only the carbon emissions, which have a main impact on the global warming potential (GWP). Additional studies are required to assess other environmental impact categories such as: acidification potential (AP), eutrophication 
potential (EP), abiotic depletion potential (ADP), ozone depletion potential (ODP), ecotoxicity (ETC), human toxicity (HTC) etc.

\section{Conclusions}

Bridges incorporating FRP decks are a relatively new and promising concept. Previous research and field applications have clearly demonstrated the benefits brought by lightweight FRP decks to the overall structural performance of bridges, especially in the case of bridge rehabilitation and upgrading. Very little has, however, been done to examine the cost efficiency and sustainability of this concept in relation to other conventional bridge concepts.

These issues are addressed in this paper through a detailed assessment of the life-cycle cost and the environmental impact of two alternative solutions considered for an existing composite (steel-concrete) bridge with a deteriorated concrete deck. The total replacement of the bridge is compared with a bridge rehabilitation scenario in which the concrete deck is replaced by an FRP deck. Based on the results of this analysis, several conclusions are drawn.

- FRP decks have the advantage of rapid erection, producing a less negative impact on users and society and improving social sustainability.

- The energy consumption and carbon emissions of bridge constructions with FRP decks are usually less than those of bridges with conventional materials. FRP materials generate higher carbon emissions than traditional materials during the production phase. This high embodied carbon emission is more than compensated for during the construction, maintenance or disposal stages, due to material savings for the supports in new bridge constructions (owing to the light weight of FRP decks), less transport for the materials, reduced on-site activities and traffic detours, making FRP decks environmentally favourable. In the case-study bridge, the total carbon emissions for the FRP deck option decreased by $20 \%$ compared with the prefabricated concrete deck option.

- In the case-study bridge analysis, substantial cost savings were achieved by considering the FRP deck as a refurbishment option instead of replacing the entire superstructure, despite the high initial cost of the FRP deck. In order additionally to offset the high initial cost of FRP decks, it would be better if the target bridges were located on high-volume roadways where user costs caused by traffic delays from construction are significant. However, an important aspect/problem with the social costs in the owner/authorities perspective is that, usually there is not funding to cover extra costs in order to reduce the social costs. It is, therefore, useful to develop a new model for public funding so that the social costs are included.

- Alternative wear surfaces with lower embodied carbon emissions other than polymer concrete (without compromising the structural integrity) would further reduce the environmental impact of bridges with FRP decks.

- According to the case-study bridge in this paper, FRP decks offer a sustainable solution for the rehabilitation of functionally obsolete bridges. 
Along with these conclusions, FRP decks will probably gain recognition due to improved social sustainability, potential cost savings over the life cycle of the bridge and promising results in terms of the environmental impact.

\section{Acknowledgements}

The work presented in this paper is part of the EU-funded PANTURA project. The authors would like to acknowledge the assistance and support provided by Ramböll $\mathrm{AB}$ (Sweden) and Fiberline Composites (Denmark).

\section{References}

1. http://www.pantura-project.eu/.

2. Haghani, R., D5.3 - Needs for maintenance and refurbishment of bridges in urban environments. PANTURA 2011.

3. Canning, L., Mount Pleasant FRP Bridge Deck Over M6 Motorway, in Fourth International Conference on FRP Composites in Civil Engineering (CICE2008)2008: Zurich, Switzerland.

4. Canning, L., et al., Progress of advanced composites for civil infrastructure. Proceedings of the Institution of Civil Engineers: Structures and Buildings, 2007. 160(6): p. 307-315.

5. Knippers, J., et al., Bridges with glass fibre-reinforced polymer decks: The road bridge in Friedberg, Germany. Structural Engineering International: Journal of the International Association for Bridge and Structural Engineering (IABSE), 2010. 20(4): p. 400-404.

6. Lee, S.W. and K.J. Hong. Opening the gate: Construction of $300 \mathrm{M}$ composite-deck bridge in Korea. in Asia-Pacific Conference on FRP in Structures (APFIS 2007). 2007.

7. Sams, M. Broadway bridge case study bridge deck application of fiberreinforced polymer. 2005.

8. Thodesen, C.C., et al., D6.4: Comparative analysis of best practices: Review of existing methods and development of an indicator suite for pantura goals. PANTURA, 2012.

9. Lee, S.W., K.J. Hong, and J.I. Kim. Use of promising composite 'Delta Deck' for various composite deck bridges. in Fourth International Conference on FRP Composites in Civil Engineering (CICE2008). 2008. Zurich, Switzerland.

10. Suzuki, T. and J. Takahashi. Prediction of energy intensity of carbon fiber reinforced plastics for mass-produced passenger cars. in The Ninth Japan International SAMPE symposium. 2005.

11. Hammond, G. and C. Jones, Inventory of Carbon and Energy (ICE) - Version 1.6a. University of Bath, 2008.

12. Daniel, R.A., A composite bridge is favoured by quantifying ecological impact. Structural Engineering International: Journal of the International Association for Bridge and Structural Engineering (IABSE), 2010. 20(4): p. 385-391. 
13. Resins, B.D.D.C., et al., LCA COMPOSIETBRUG Eindrapport (2e versie) VERTROUWELIJK. BECO Groep, Vestiging Rotterdam, mei 2009, 2009.

14. Tanaka, H., et al. A case study on life-cycle assessment of environmental aspect of FRP structures. in Third International Conference on FRP Composites in Civil Engineering (CICE 2006). 2006. Miami, Florida, USA.

15. Zhang, C., M. Amaduddin, and L. Canning, Carbon dioxide evaluation in a typical bridge deck replacement project. Proceedings of Institution of Civil Engineers: Energy, 2011. 164(4): p. 183-194.

16. Patel, M. and N. Mutha, Plastics Production and Energy, in Encyclopedia of Energy, J.C. Editor-in-Chief: Cutler, Editor. 2004, Elsevier: New York. p. 81-91.

17. Correia, J.R., N.M. Almeida, and J.R. Figueira, Recycling of FRP composites: Reusing fine GFRP waste in concrete mixtures. Journal of Cleaner Production, 2011. 19(15): p. 1745-1753.

18. Ehlen, M.A., Life-cycle costs of fiber-reinforced-polymer bridge decks. Journal of Materials in Civil Engineering, 1999. 11(3): p. 224-230.

19. Kendall, A., G.A. Keoleian, and G.E. Helfand, Integrated life-cycle assessment and life-cycle cost analysis model for concrete bridge deck applications. Journal of Infrastructure Systems, 2008. 14(3): p. 214-222.

20. Sahirman, S., R.C. Creese, and H.V.S. GangaRao. FRP bridge deck life cycle cost analyzer. 2008. Varenna, Lake Como.

21. Nystrom, H.E., et al., Financial viability of fiber-reinforced polymer (FRP) bridges. Journal of Management in Engineering, 2003. 19(1): p. 2-8.

22. Nishizaki, I., et al., A Case Study of Life Cycle Cost based on a Real FRP Bridge. Third International Conference on FRP Composites in Civil Engineering (CICE 2006), 2006.

23. Triandafilou, L.N. and J.S. O'Connor, Field issues associated with the use of fiber-reinforced polymer composite bridge decks and superstructures in harsh environments. Structural Engineering International: Journal of the International Association for Bridge and Structural Engineering (IABSE), 2010. 20(4): p. 409-413.

24. Nilsson, M., Samverkansbroar ur ett samhällsekonomiskt perspektiv 2002.

25. Mara, V., M. Al-Emrani, and R. Kliger. Upgrading of an existing concretesteel bridge using fibre reinforced polymer deck- A feasibility study. in FRP Bridges Conference. 2012. London, UK.

26. Hjort, C. and M. Tenskog, Vägverkets samhällsekonomiska kalkylvärden. Vägverket, 2008(2008:67): p. 1401-9612.

27. www.fiberline.com.

28.

https://batman.vv.se/batman/logon/logon.aspx?url=https://batman.vv.se/ batman/. 
29. Chandler, R.F., Life-Cycle Cost Model for Evaluating the Sustainability of Bridge Decks. Center for Sustainable Systems, University of Michigan 2004. CSS04-06: p. 1-116.

30. Tanaka, H., et al., A case-study on life-cycle assessment of environmental aspect of FRP structures. Third International Conference on FRP Composites in Civil Engineering (CICE 2006), 2006.

31. (EA), E.A., Carbon calculator for construction activities. Environment Agency, London, 2007. 
